\title{
Avaliação da exposição ocupacional ao mercúrio num grupo de cirurgiões-dentistas da unidade sede do sesc de porto alegre.
}

\author{
Assessment of the occupational exposure to mercury \\ in dental surgeons at sesc headquarters in porto alegre.
}

\author{
${ }^{*}$ Carmen Beatriz Borges Fortes \\ *Elson Romeu Farias \\ * Jiovana Friedrich \\ *Silvio Henrique Lafin Junior \\ **Damasio Trindade \\ ${ }^{* * *}$ Lisia Maria Fensterseifer
}

\section{RESUMO}

O objetivo deste estudo foi realizar a análise de frequência dos dados obtidos de um questionário estruturado, e dos níveis de mercúrio encontrados na urina de 51 cirurgiōes-dentistas, da unidade Sede do SESC, de Porto Alegre, em 1997. A análise dos dados mostrou que os cirurgiōes-dentistas apresentam exposição ocupacional ao mercúrio, pois a maioria deles apresentou níveis de mercúrio acima do valor de referência da normalidade, que é de 5 ug de mercúrio/g de creatinina, apesar de inferiores aos níveis de tolerância máxima permitida, que é de 35 ug de mercúrio/g de creatinina.

\section{UNITERMOS}

Exposiçāo ocupacional ao mercúrio, toxicidade do mercúrio, odontologia, cirurgião-dentista.

\section{I - INTRODUÇÃO}

Amálgama é toda a liga metálica em que um dos componentes é o mercúrio metálico. $\mathrm{Na}$ odontologia o amálgama mais utilizado é o amálgama de prata, cuja composição, dependendo do tipo de liga, é de aproximadamente $50 \%$ de mercúrio(15).

O mercúrio é um metal pesado, cujo vapor não apresenta cor, odor ou sabor $e$, portanto não pode ser detectado por meios simples, mesmo nos níveis próximos aos da exposição máxima (14). Devido a estas propriedades entende-se porque o mercúrio torna-se um risco em potencial à saúde dos cirurgiōes-dentistas, e um risco de contaminação do ambiente de trabalho.

O cirurgiâo-dentista que trabalha com amálgama está exposto ao vapor de mercúrio, nas seguintes etapas deste processo de trabalho (7):

1 - preparação do amálgama,

2 - restauração do preparo cavitário com amálgama,

3 - polimento da restauração de amálgama,

4 - remoção da restauraçāo de amálgama,

5 - descarte dos resíduos de amálgama,

6 - armazenagem do mercúrio.

O presente estudo tem como objetivo avaliar a exposição ocupacional ao mercúrio, num grupo de cirurgiōes-dentistas da unidade Sede do SESC de Porto Alegre, através da análise de frequência do número de anos de exposiçāo ao mercúrio, do uso de EPI, e dos níveis de mercúrio encontrados na urina destes profissionais.

\section{2 - REVISÃO DA LITERATURA}

A exposiçáo ao mercúrio pode ocorrer através das vias respiratória, digestiva ou cutânea, na forma de vapores ou finas partículas mercuriais. O mercúrio elementar após ser absorvido é parcialmente oxidado formando mercúrio iônico nos eritrócitos e nos tecidos (14). Devido a elevada difusibilidade e lipossolubilidade do mercúrio, cerca de $80 \%$ do vapor de mercúrio fica retido nos pulmões (3).

$O$ sistema nervoso central e os rins são os órgãos mais atingidos nas exposiçōes de longo prazo. Mas como o mercúrio distribui-se no sangue pode atingir vários órgãos.

A eliminação do mercúrio se dá através da urina e das fezes, mas pequenas quantidades podem ser eliminadas pelo suor, pela saliva, pela lágrima e pelos cabelos.

O material biolólogico utilizado para avaliar exposição ocupacional ao mercúrio metálico é a urina. Este é o indicador biológico usado no Brasil e consta na Norma Regulamentadora(NR) número $7 \mathrm{da}$ portaria 3214 do Ministério do trabalho de 1978 (18).

Os sinais e sintomas de interesse ocupacional descritos na literatura estão relacionados com o tempo de exposição e a concentração de vapor de mercúrio no ambiente de trabalho.
A exposição aguda ao mercúrio está relacionada com os seguintes sintomas cansaço, náuseas e/ou vômitos, cefaléia, distúrbios visuais, febre, calafrios, dor abdominal, diarréia, dispnéia, cianose, edema pulmonar e retardo na condução nervosa (14).

A exposição crônica está relacionada com manifestações do sistema nervoso central como excitabilidade, insônia, perda de memória, irritabilidade, ansiedade, perda do autocontrole, depressão e tremores que desaparecem com o sono. Os casos graves podem apresentar delírio, alucinação, melancolia, ideação suicida e quadros de psicose maníaco depressiva. Neste tipo de exposição, as manifestaçóess orais mais frequentes são a gengivite, a estomatite e a sialorréia. Ao cessar a exposição ao mercúrio, os sintomas desaparecem gradualmente, embora não se tenha certeza da irreversibilidade dos sintomas psiquicos e das desordens ocasionadas no sistema nervoso central (14).

A exposição a baixas concentraçōes, mas durante um longo período de tempo, caracteriza o micromercurialismo, que é a situação ocupacional presente na Odontologia. Neste tipo de exposiçāo o profissional pode apresentar queda de produtividade, aumento da fadiga, irritabilidade nervosa, perda de memória, além de outros sintomas que estão presentes nas intoxicaçōes por outros metais pesados (14).

Em relação à exposição ocupacional, os cirurgiōes-dentistas estão entre aqueles profissionais que mais destaque recebem frente

* Médicos e alunos do Curso de Especialização em Medicina do Trabalho da UFRGS.

**Médico e Chefe do Ambulatório de Doenças Profissionais do HCPA.

***Livre Docente em Educação e Professora do Curso de Especialização em Medicina do Trabalho.

R. Fac. Odontol., Porto Alegre, v. 40, n. 1, p. 18-21, set. 1999 
à exposição ao vapor de mercúrio (9).

A absorção de mercúrio pela equipe de Odontologia tem sido conhecida através da análise de mercúrio na urina e no sangue (2) e também da análise feita nos cabelos e unhas $(10,13)$. Estes autores referem que foram encontrados níveis mais elevados de mercúrio na urina dos membros da equipe dentária se comparados com os da população em geral.

A equipe dentária pode estar momentaneamente exposta a altos níveis de mercúrio durante a manipulação, restauração, polimento e remoção das restauraçóes de amálgama, se medidas de proteção adequada nāo forem usadas $(6,7,8,16)$.

\section{3 - METODOLOGLA}

Este estudo é de natureza descritiva e quantitativa $e$ foi desenvolvido num grupo de cirurgiōes-dentistas, que trabalham na unidade Sede do Serviço Social do Comércio (SESC) de Porto Alegre.

\section{1 - Coleta de dados: os dados foram coletados em duas etapas.}

A primeira etapa realizou-se junto aos cirurgiōes-dentistas, os quais receberam um questionário estruturado e um termo de consentimento informado. Dos 54 cirurgióesdentistas que trabalham nesta unidade, 51 responderam aos quesitos solicitados. Através do questionário buscou-se pesquisar o número de anos de exposição ao mercúrio, e o uso de equipamento de proteção individual, entre outros, porém o enfoque do presente trabalho está voltado para estes dois itens.

A segunda etapa foi realizada junto ao Médico do Trabalho desta unidade, que forneceu os resultados da última dosagem de mercúrio realizada nos cirurgióes-dentistas. A cada seis meses, este exame é realizado para se fazer o monitoramento biológico destes profissionais frente à exposição ao mercúrio. Este exame faz a análise da concentração de mercúrio na urina através da espectrofotometria de absorção atômica.

\section{2 - Aspectos éticos}

A preocupação em preservar os aspectos éticos que o estudo envolvia esteve sempre presente, no sentido de garantir o resguardo da identidade dos cirurgiōes-dentistas que concordaram em participar do estudo.

\section{3 - Análise dos dados}

A análise dos dados desta pesquisa foi feita através da distribuição de freqüência.

\section{4 - RESULTADOS E DISCUSSĀO}

Os dados obtidos através do questionário estruturado, e da dosagem de mercúrio na urina são descritos na sequência abaixo.

A pesquisa foi realizada com 51 cirurgióesdentistas com idade na faixa de 23 a 53 anos, com média de 40 anos e desvio-padrão de 9,3 anos.

Destes 35 (69\%) são do sexo femininoe 16 (31\%) do sexo masculino, conforme o gráfico 1 .

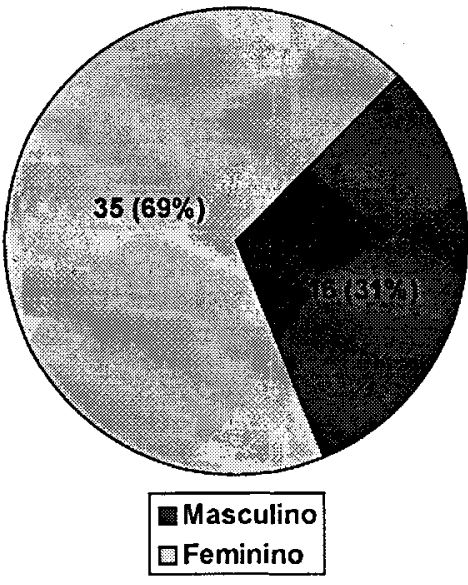

Gráfico 1 - Distribuição por sexo

O tempo de exposição ao mercúrio da populaçāo estudada foi de 1 a 31 anos, sendo que a média foi de 16,7 anos, com desvio padrão de 8,63 anos e $72,6 \%$ da amostra teve mais de 10 anos de exposição, de acordo com o gráfico 2.

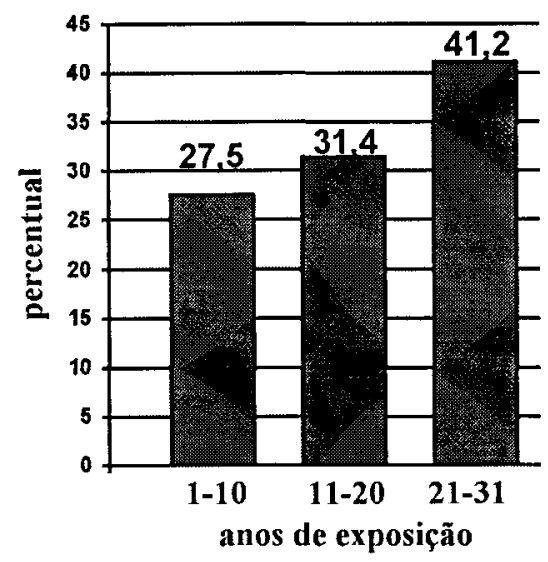

Gráfico 2 - Distribuição

por anos de exposiçăo ao mercúrio

Em relação ao trabalho com o amálgama, constatou-se que 32 cirurgiōes-dentistas (63\%) utilizam este material no SESC, conforme o gráfico 3, e acrescentando-se a estes os que trabalham em outro local com o amálgama, este número eleva-se para 47 (92\%). Os cirurgiōes-dentistas da unidade Sede do SESC realizaram uma média de 10.000 atendimentos no mês em que foi feito este levantamento de dados. Destes atendimentos $20 \%$ envolveram restauraçōes de amálgama.

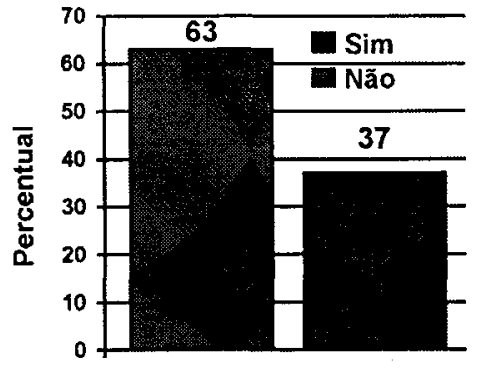

Gráfico 3 - Trabalho com amálgama no SESC
As restauraçōes de amálgama sāo feitas até os dias de hoje, sendo utilizadas nas restaurações de dentes posteriores por $92 \%$ dos cirugiões-dentistas americanos $(4,16)$.

No Reino Unido, aproximadamente 2? milhões de restaurações de amálgama foram feitas a cada ano na década de 80 (5).

Mais de 100 milhōes de restauraçōes de amálgama são realizadas a cada ano nos EUA e, o longo tempo de uso e a popularidade deste material continuam oferecendo evidências de que ele é seguro (1).

Quanto ao uso de equipamento de proteção individual constatou-se que todos os cirurgiões-dentistas usam avental (100\%); 50 (98\%) usam luvas; 47 (92\%) usam máscara e $46(90 \%)$ usam óculos de proteção, de acordo com o gráfico 4 .

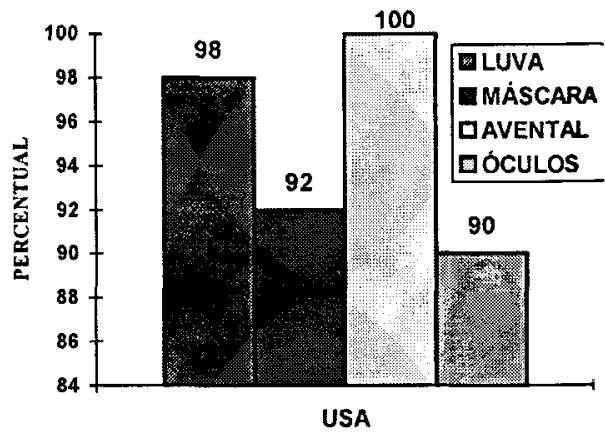

Gráfico 4 - Uso de equipamento de proteção individual

A Norma Regulamentadora $n^{\circ} 6$ refere que a Empresa é obrigada a fornecer aos empregados, gratuitamente, equipamento de proteção individual adequado as suas atividader profissionais, e estes devem usá-lo (18). Em nossc estudo constatou-se que esta Norm: Regulamentadora está sendo apenas parcialmente cumprida, visto que nem todos o: cirurgiōes-dentistas usam a tototalidade do: equipamentos de proteção individual que sāo fornecidos pela empresa.

$\mathrm{Na}$ análise de mercúrio na urina nã foi encontrada nenhuma dosagem acima d: índice biológico máximo permitido (IBMP 35,0 ug de mercúrio/g creatinina). Er: quatorze cirurgiōes-dentistas $(27,4 \%)$ o: níveis foram de 5,0 ug de mercúrio creatinina, que é o valor de referência d: normalidade (VR). Trinta e três $\left(64,7{ }^{a}\right.$ apresentaram níveis entre 5,1 e $10,0 \mu \mathrm{g} / \mathrm{g} \mathrm{c}$. creatinina, três $(5,9 \%)$ tinham niveis ent: 10,1 e $15,0 \mu \mathrm{g} / \mathrm{g}$ de creatinina e um $(2 \%$ tinha o seu nivel entre 15,1 e $20,0 \mu \mathrm{g} / \mathrm{g}$ c creatinina.Portanto, trinta e sete cirurgiōe: dentistas $(72,5 \%)$ apresentaram niveis $d$ : mercúrio na urina entre 5,1 e 34,9 ug : creatinina, estando acima do VR e abaixo d: IBMP. O valor médio da concentraçāo $\dot{c}$ : mercúrio na urina foi de $16,7 \mathrm{ug} / \mathrm{g}$ creatinin: com desvio-padrão de $8,63 \mathrm{ug} / \mathrm{g}$ creatinin: de acordo com o gráfico 5 . 


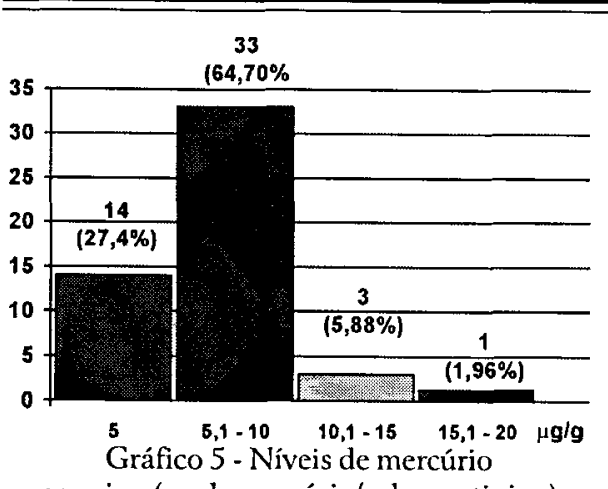

na urina (ug de mercúrio/g de creatinina)

Os resultados de várias pesquisas realizadas nos Estados Unidos entre 1985 e 1995, que incluíam a dosagem de mercúrio no sangue e na urina dos cirurgióes-dentistas mostraram que: entre 1975 e 1983 , a média de mercúrio na urina foi de $14,2 \mathrm{ug} / \mathrm{L}$; entre 1985 e 1986 a média foi entre 5,8 e $6,7 \mathrm{ug} / \mathrm{L}$ e em 1995 a média foi de $4,94 \mathrm{ug} / \mathrm{L}$. Esta diminuição dos níveis urinários de mercúrio ocorreram após uma campanha agressiva sobre a higiene do mercúrio instituida pela $\mathrm{ADA}$, que tinha por finalidade reduzir os níveis de mercúrio no ambiente e também a sua absorção pelo cirurgiāo-dentista, minimizando os riscos da exposição ocupacional destes profissionais $(I 1,12)$.

Estudos realizados em 120 cirurgiõesdentistas onde foram determinados os niveis de mercúrio, de proteínas, de sódio e de potássio em amostras de urina, mostraram que $40 \%$ dos profissionais tinham níveis de mercúrio superiores a $10 \mu \mathrm{g} / \mathrm{L}$, portanto, acima do valor de referência (que na época deste estudo era de $10 \mu \mathrm{g} / \mathrm{L}$ de urina). Este estudo também mostrou que $1,6 \%$ deles tinham níveis superiores a 50 $\mu \mathrm{g} / \mathrm{L}$, portanto acima do índice biológico máximo permitido aceito nesta época, que era de $50 \mu \mathrm{g} /$ L de urina (17).

A Organizaçāo Mundial de Saúde mostra que há uma boa evidência epidemiológica de que a exposiçāo ocupacional recente se reflete nos níveis de mercúrio encontrados no sangue e na urina dos profissionais expostos (9).

Durante a última década, houve uma grande preocupação com a exposiçāo ao mercúrio e uma série de cuidados foram tomados para reduzir esta exposição, o que levou a uma redução de mais de $50 \%$ na concentração de mercúrio na urina dos profissionais da Odontologia (12).

Com o advento de equipamentos apropriados para a manipulação do amálgama, o uso de equipamento de proteção individual(EPI) e uma adequada higiene do mercúrio,os riscos de exposição aos vapores de mercúrio têm sido minimizados (7).

Os resultados desta pesquisa mostraram que os cirurgiōes-dentistas da unidade Sede do SESC de Porto Alegre estāo expostos ao mercúrio, pois embora apresentem baixas concentrações de mercúrio na urina, na maioria dos profissionais, estas estavam acima do valor de referência da normalidade, que é de $5 \mu \mathrm{g}$ de mercúrio/g de creatinina.

\section{5 - CONCLUSÕES}

A maioria dos estudos revisados mostram que os cirurgióes-dentistas apresentam exposição ocupacional ao mercúrio e que os níveis urinários de mercúrio refletem as concentraçóes de mercúrio do ar ambiente. Apesar dos níveis urinários de mercúrio representarem baixos índices de contaminação ocupacional, a mesma ocorre de forma contínua durante os anos de atividade profissional. Por outro lado, devemos considerar a existência daqueles indivíduos mais sensíveis, que poderão apresentar alterações orgânicas significativas, conseqüentes da interação agente tóxico-organismo, mesmo que essa interação resulte de baixos niveis de exposição. Mas não devemos exagerar e nem negligenciar nesta relaçāo existente entre os níveis de mercúrio na urina e a saúde dos profissionais da Odontologia, pois uma série de fatores, como o uso de equipamento de proteção individual, as condiçôes do ambiente de trabalho e uma técnica de manipulação adequada do amálgama e/ou mercúrio podem influenciar nos níveis de mercúrio que são absorvidos pelo organismo humano.

Os resultados da pesquisa demonstraram que os cirurgióes-dentistas apresentam exposição ocupacional ao mercúrio e, embora estes níveis não tenham ultrapassado o índice biológico máximo permitido, que é de $35 \mu \mathrm{g}$ de mercúrio/ $\mathrm{g}$ de creatinina, a maioria deles apresentou níveis acima do valor de referência da normalidade, que é de $5 \mu \mathrm{g}$ de mercúrio/g de creatinina. Portanto, o problema da contaminação por mercúrio nos consultórios dentários merece atenção, não somente devido ao grande número de profissionais envolvidos, mas sobretudo pela forma com que o mercúrio é manipulado e/ou tratado, e também porque o uso de medidas de proteção efetivas e uma correta higiene do mercúrio podem diminuir os níveis de exposiçāo. Os cirurgiões-dentistas pesquisados recebem da empresa equipamento de proteção individual, e constatou-se que o seu uso foi significativo, o que deve ter minimizado a exposição ocupacional destes profissionais, que apresentaram baixas concentrações de mercúrio na urina.

Os resultados desta pesquisa não podem ser tomados como universais, pois são válidos para este grupo específico, que se encontra dentro de um contexto de trabalho muito particular.

\section{SUMMARY}

The aim of this study was to analyse the data obtained from a structured questionaire, and the mercury levels found in the urine of 51 dental-surgeons at the SESC headquarters in Porto Alegre in 1997. The analysis of data showed that dental-surgeons had occupational exposition to mercury, whereas most of them showed levels of mercury above the reference value of normality, which is $5 \mathrm{ug} / \mathrm{g}$ creatinine, despite of this, it is still lower than the maximum allowable level which is $35 \mathrm{ug} / \mathrm{g}$ creatinine.

\section{KEYWORDS}

Occupational exposition to mercury, mercury toxicity, dentistry, dental-surgeons.

\section{6- REFERÊNCLAS BIBLIOGRÁFICAS}

01- AMERICAN DENTAL ASSOCLATION. Divisions of Communication and Scientific Affairs. When your patients ask about mercury in amalgam? J. Am. Dent. Assoc. . Chicago, v. 120, n. 4, p. 395. 398, Apr. 1990.

02 - BATTISTONE, G. C.; HEFFERREN, J. J.; MILLER, R. A. et al. Mercury: its relation to the dentist's health and dental practice characteristics. J. Am. Dent. Assoc., Chicago, v. 92, n. 6, p. 1182 1188, June, 1976

03 - BAUER, J. G.; FIRST, H. A. The Toxicity of Mercury in Dental Amalgam. CDA J., Los Angeles, v. 10. n. 6, p. 47-61, June, 1982.

04 - BERRY, T. G; NICHOLSON, J.; ENGLE, K Almost two Centuries with Amalgam: where are we today? J. Am. Dent. Assoc., Chicago, v. 125, n. 4, p. 392-399, Apr. 1994

05- COMPENDIUM of health statistics. 7.ed. London: Office of Health Economics, 1989. p. 80.

06 - COOLEY, R. L.; LUBOW, R. M. Mercury Vapor Emitted from Disposable Capsules Placed in Trash Containers. Gen. Dent., Chicago, v. 33, n. 6, p. 498-500, Nov/Dec. 1985.

07 - ELEY, B. M. The Future of Dental Amalgam: a review of the literature. Part $2:$ Mercury exposure in dental practice. Br. Dent. J., London, v. 182 , n. 8, p. 293-297, Apr. 1997.

08 - FRYKHOLM, K. O. Exposure of Dental Personnel to Mercury During Work. A Comparative Study Using Advanced Analytical Methods. Sven. Tandlak. Tidskr., Stockholm, v. 63, n. 11, p. 763-772, Nov. 1970

09- INORGANIC mercury. Geneva : World Health Organization, 1991.(Environmemtal Health Criteria, 118)

10. LENIHAN, J. M. A.; SMITH, H.; HARVEY, W. Mercury Hazards in Dental Practice: Assessment and control by activation analysis. Br. Dent. J .. London, v. 135, n. 8, p. 365-369, Oct. 1973.

11- MARTIN, M. D.; NALEWAY, C.; CHOU H-N. Factors Contributing to Mercury Exposure in Dentists. J. Am. Dent. Assoc., Chicago, v. 126, n. 11, p. 1502-1511, Nov. 1995

12 - NALEWAY, C.; CHOU, H-N.; MULLER, T. et al. On-site Screening for Urinary $\mathrm{Hg}$ Concentrations and Correlation with Glomerular and Renal Tubular Function. J. Public. Health Dent., Raleigh, v. 51, n. 1, p. 12-17, Winter, 1991.

13 - NIXON, G. S. ; WHITTLE, C. A. ; WOODFIN, A. Mercury Levels in Dental Surgeries and Dental Personnel. Br. Dent. J., London, v. 151, n. 5, p. I49-154, Sept. 1981.

14. OGA, S. (Ed.) Fundamentos de Toxicologia. Sāo Paulo: Atheneu, 1996.

15 - PHILLIPS, R. W. Materiais Dentários de Skinner. 9.ed. Rio de Janeiro : Guanabara Koogan, 1993.

16 - REINHARDT, J. W. Risk Assessment of Mercury Exposure from Dental Amalgam. J. Pub. Health. Dent., Raleigh, v. 48, n. 3, p. 172-177, Summer. 1988.

17 - SALGADO, P. E. T. et al. Determinaçāo do Mercúrio, Proteínas, Sódio e Potássio em Amostras de Urina de Cirurgiōes-Dentistas Expostos Ocupacionalmente. Rev. Bras. Saúde Ocup., São Paulo, v. 14, n. 56, p. 7-1 1, out/now/ dez., 1986.

18 - SEGURANCCA e Medicina do Trabalho 36.ed. Si Paulo : Atlas, 1997. (Manuais de Legislayio Atlas, 16) 